\title{
Características biológicas y seguimiento clínico en casos naturales de tumor venéreo transmisible canino
}

\section{Biological characteristics and clinical follow-up in natural cases of canine transmissible venereal tumour}

\author{
Juan C. Ramírez-Ante ${ }^{1,2}$, Andrés Fernández-Riomalo ${ }^{1,2,3}$, \\ Francisco J. Pedraza-Ordoñez ${ }^{1,4}$
}

\section{Resumen}

El objetivo de este estudio fue evaluar si existe alguna relación entre los subtipos citológicos, las fases histopatológicas y la respuesta al tratamiento con sulfato de vincristina en caninos afectados naturalmente por el tumor venéreo trasmisible canino (TVTC). Se evaluaron 52 casos de TVTC en diferentes razas, edades y sexo sin encontrar una relación significativa entre las clasificaciones citológicas e histopatología determinadas previas a la quimioterapia y el tiempo de duración de este. Los resultados no mostraron diferencias en factores como respuesta parcial al tratamiento, grado de malignidad, metástasis o resistencia a la vincristina en los perros tratados; además, no se pudo definir el pronóstico para la involución tumoral a partir de la clasificación citología o histopatológica.

Palabras clave: fases histopatológicas, involución tumoral, quimioterapia, subtipos citológicos, tumor venéreo trasmisible canino

${ }^{1}$ Grupo de Investigación en Patología Veterinaria, Facultad de Ciencias Agropecuarias, Universidad de Caldas, Manizales, Colombia

${ }^{2}$ Facultad de Ciencia Pecuarias, Corporación Universitaria Santa Rosa de Cabal UNISARC, Santa Rosa de Cabal, Colombia

${ }^{3}$ Facultad de Medicina Veterinaria y Zootecnia, Fundación Universitaria Autónoma de las Américas, Pereira, Colombia

${ }^{4}$ Laboratorio de Patología Animal, Departamento de Salud Animal, Universidad de Caldas, Manizales, Colombia

${ }^{5}$ E-mail: juan.ante@unisarc.edu.co

Recibido: 8 de agosto de 2020

Aceptado para publicación: 6 de febrero de 2021

Publicado: 24 de abril de 2021 
The aim of this study was to evaluate whether there is any relationship between cytological subtypes, histopathological phases, and the response to vincristine sulfate treatment in canines naturally affected by canine transmissible venereal tumour (CTVT). In total, 52 cases of CTVT were evaluated in different breeds, ages and sex without finding a significant relationship between the cytological classifications and histopathology determined prior to chemotherapy and the duration of the chemotherapy. The results of did not show differences in factors such as partial response to treatment, degree of malignancy, metastasis or resistance to vincristine in treated dogs, and the prognosis for tumour involution could not be defined from the cytology or histopathological classification.

Key words: histopathological phases, tumour involution, chemotherapy, cytological subtypes, canine transmissible venereal tumour

\section{INTRODUCCIÓN}

El tumor venéreo transmisible canino (TVTC) es una neoplasia que se presenta en caninos y que se transmite por una transferencia alogénica de células cancerígenas vivas durante el coito (Strakova y Murchison, 2015), aunque también puede transmitirse mediante el lamido y olfateo (Murchison, 2009; Castro et al., 2017). TVTC es endémico en al menos 90 países y se cree que es la célula tumoral más diseminada y longeva que existe (Strakova y Murchison 2014; Ostrander et al., 2016), presentándose principalmente en caninos que viven o tienen acceso permanente a la calle (Sousa et al., 2000). El análisis del genoma del TVTC ha permitido esclarecer su origen y evolución ubicándolo como el cáncer en caninos más antiguo hasta ahora conocido (Murchison et al., 2014).

El diagnóstico se realiza por las manifestaciones clínicas de la neoplasia, como son textura friable con aspecto de coliflor, nodular o multilobulado (Ganguly et al., 2013). Asimismo, la observación de las células tumorales por citología e histopatología suele ser suficiente para determinar la patología; sin embargo, el diagnóstico molecular es oportuno para confirmar el caso, siendo esta una he- rramienta útil en aquellos casos de difícil diagnóstico (Castro et al., 2017). En la rutina clínica se utiliza el examen citológico mediante la técnica Biopsia Aspirativa con Aguja Fina (BACAF), que permite clasificar la neoplasia como de células redondas con los subtipos linfocitoide y plasmocitoide o una mezcla de ambos llamada mixto (Amaral et al., 2007; Montoya et al., 2012).

Algunos autores afirman que el tumor que presenta un patrón celular plasmocitoide es más difícil para el manejo médico, requiriendo un mayor número de sesiones de quimioterapia en comparación con los otros subtipos, e inclusive puede llegar a presentar resistencia al tratamiento y hacer metástasis (Gaspar et al., 2009; Valençola et al., 2015; Setthawongsin et al., 2018). En la citología se puede hallar, además, infiltrado inflamatorio como neutrófilos, linfocitos y macrófagos, sobre todo en aquellos pacientes con contaminaciones secundarias asociadas a bacterias, hongos o parásitos (Santos et al., 2005; Stockmann et al., 2011).

Estudios de trasplante experimental caracterizan clínicamente el TVTC de acuerdo con los periodos de crecimiento en tres fases: progresión, estacionaria y regresión (Epstein y Bennett, 1974; Frampton et al., 

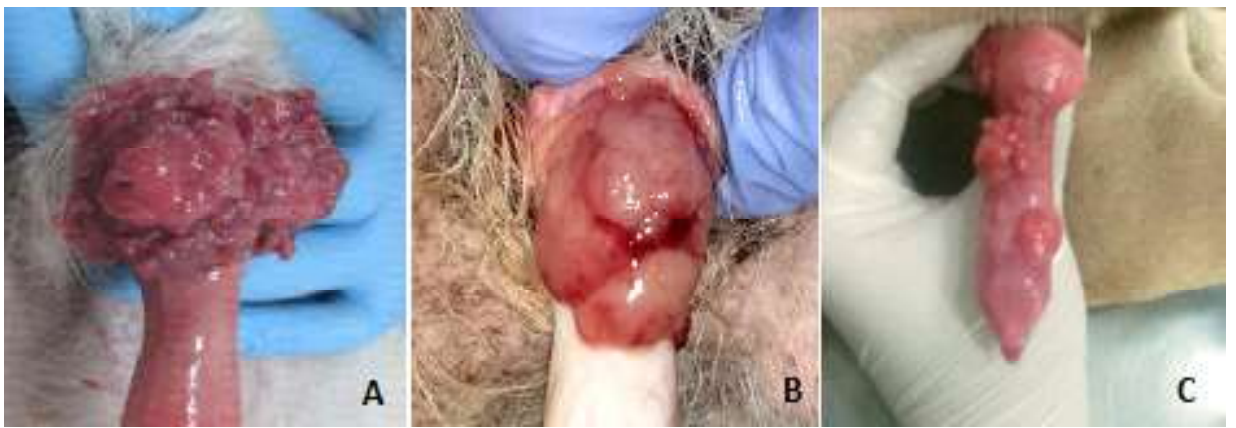

Figura 1. Formas de presentación macroscópica del tumor venéreo transmisible canino (TVTC) en canes pacientes del Hospital Veterinario de la Universidad de Caldas (Colombia): A, masa como coliflor; $\mathrm{B}$, nodular; $\mathrm{C}$, multilobulado

2018). De otra parte, en el examen histopatológico se han usado fases con los nombres de progresión, regresión temprana y regresión tardía, identificando para cada una ellas sus respectivas características de crecimiento y tisulares (Epstein y Bennett, 1974; Yang et al., 1987; Mukaratirwa et al., 2004). El protocolo terapéutico establecido para el TVTC con mayor éxito es el sulfato de vincristina como único fármaco, siendo una aplicación semanal a dosis de $0.5-0.7 \mathrm{mg} / \mathrm{m}^{2}$, administrando entre 4 a 8 dosis vía intravenosa (Oliveira et al., 2013; Otter et al., 2015).

El objetivo de este trabajo fue evaluar la posible relación de la clasificación de los subtipos citológicos y las fases histopatológicas del TVTC con la respuesta al tratamiento que permita inferir el número de quimioterapias requeridas hasta alcanzar la regresión total tumoral, permitiendo así establecer un factor pronóstico desde el diagnóstico. En el conocimiento de los autores, aún no se cuenta con un sistema que permita usar los subtipos citológicos como un factor de pronóstico del comportamiento biológico de la neoplasia.

\section{Materiales Y MéTodos}

\section{Animales}

Mediante un estudio descriptivo, longitudinal, prospectivo, que fue aprobado por el Comité de Ética y Bienestar Animal de la Facultad de Ciencias Agropecuarias, Universidad de Caldas, Colombia (Código 1065017), se evaluaron 52 caninos de diferentes razas, edades y sexo, que llegaron al Hospital Veterinario naturalmente enfermos por TVTC genital con masas friables, de tamaño variable, únicas o múltiples y morfológicamente caracterizadas por ser parecidas a coliflor y algunas veces, uni o multinodulares (Figura 1). Algunos de los animales tenían propietario; sin embargo, la mayoría, provenía de albergues de protección de animales y habían sido recogidos de la calle entre agosto de 2014 y marzo de 2017. Todos los animales se mantuvieron en el bioterio con alimento y agua a voluntad durante el tiempo que duró la investigación. 


\section{Diagnóstico Citológico}

Las células neoplásicas se obtuvieron por aspiración con aguja fina (BACAF) yfueron coloreadas con Diff quick ${ }^{\circledR}$ durante 6 minutos. Los extendidos celulares en láminas de vidrio se observaron con microscopio de luz Leica DM500 (objetivo 40X), seleccionando aleatoriamente 10 campos en los que había cantidad suficiente de células tumorales. Se tomaron fotografías con el software Leica Application Suite v. 3.1 (LAS EZ) ${ }^{\circledR}$ que fueron evaluadas por tres observadores que no conocían a que paciente correspondía cada caso con el fin de disminuir la subjetividad de observación y el sesgo en los resultados.

Los subtipos citológicos se clasificaron como propusieron Amaral et al. (2007); esto es subtipo linfocitoide: células de TVTC con forma redonda, citoplasma escaso y finamente granular, presencia de vacuolas en la periferia celular, núcleo redondo con cromatina gruesa y presencia de uno o dos nucléolos; y subtipo plasmocitoide: células de forma ovoide, citoplasma abundante con presencia de muchas vacuolas y núcleo excéntrico (Figura 2). De cada subtipo citológico se analizaron 50 células para mejorar su descripción morfológica. Debido a que los dos tipos de células están presentes en todos los casos, el criterio para definir el nombre de cada subtipo corresponde a un predominio superior al $60 \%$ de ese subtipo celular en los campos evaluados. A los casos donde no predomina ningún tipo de célula, les denominan subtipo mixto.

\section{Diagnóstico Histopatológico}

Antes de iniciar el tratamiento quimioterapéutico para cada paciente, se obtuvo una biopsia del tumor en condiciones asépticas. Los animales permanecieron bajo anestesia general mientras se realizaba el procedimiento. Las muestras fueron introducidas en crioviales estériles y sumergidas en $1 \mathrm{ml}$ de formalina tamponada al $10 \%$ durante $48 \mathrm{~h}$ para posteriormente ser parafinadas en un procesador automático de tejidos $\left(\operatorname{Kedee}^{\circledR}\right)$. Cortes tisulares de $4 \mu \mathrm{m}$ se obtuvieron con un micrómetro Leica RM $2135^{\circledR}$, los tejidos fueron coloreados con hematoxilina y eosina para determinar el estado de crecimiento tumoral y con tricómico de Masson para facilitar la observación del tejido conectivo. La observación aleatoria de cinco campos se hizo por tres observadores (estudio ciego) con el objetivo de 10X en el microscopio de luz, tomando como resultado la coincidencia de por lo menos dos observadores.

La clasificación histopatológica usada en la presente investigación se realizó acorde a las tres etapas histológicas del TVTC establecidas por Mukaratirwa et al. (2004): a) Progresión (P), caracterizada por ser un tumor que aumenta constantemente de volumen, presencia de poco estroma, abundantes células neoplásicas en mitosis y poco infiltrado linfocitario; b) Regresión temprana (ER), donde el tumor disminuye rápidamente de volumen, presentando algunas células neoplásicas en mitosis, aumento de células apoptóticas e incremento del infiltrado linfocitario; y c) Regresión tardía (LR), en la cual el tumor disminuye su volumen lentamente, presentando abundante infiltrado linfocitario, desparecen las células neoplásicas, depósitos de colágeno y remplazo por estroma fibroso (Figura 3).

\section{Diagnóstico Molecular}

En biopsias mantenidas en RNA Latter, todos los casos fueron confirmados como TVTC por qPCR mediante la identificación de un reordenamiento característico que implica un largo intercalado elemento nuclear (LINE) ubicado cerca al locus MYC (Castro et al., 2017; Setthawongsin et al., 2018). Estas muestras fueron analizadas por el grupo de investigación en Cáncer Transmisible del departamento de Medicina Veterinaria en la Universidad de Cambridge Inglaterra. 

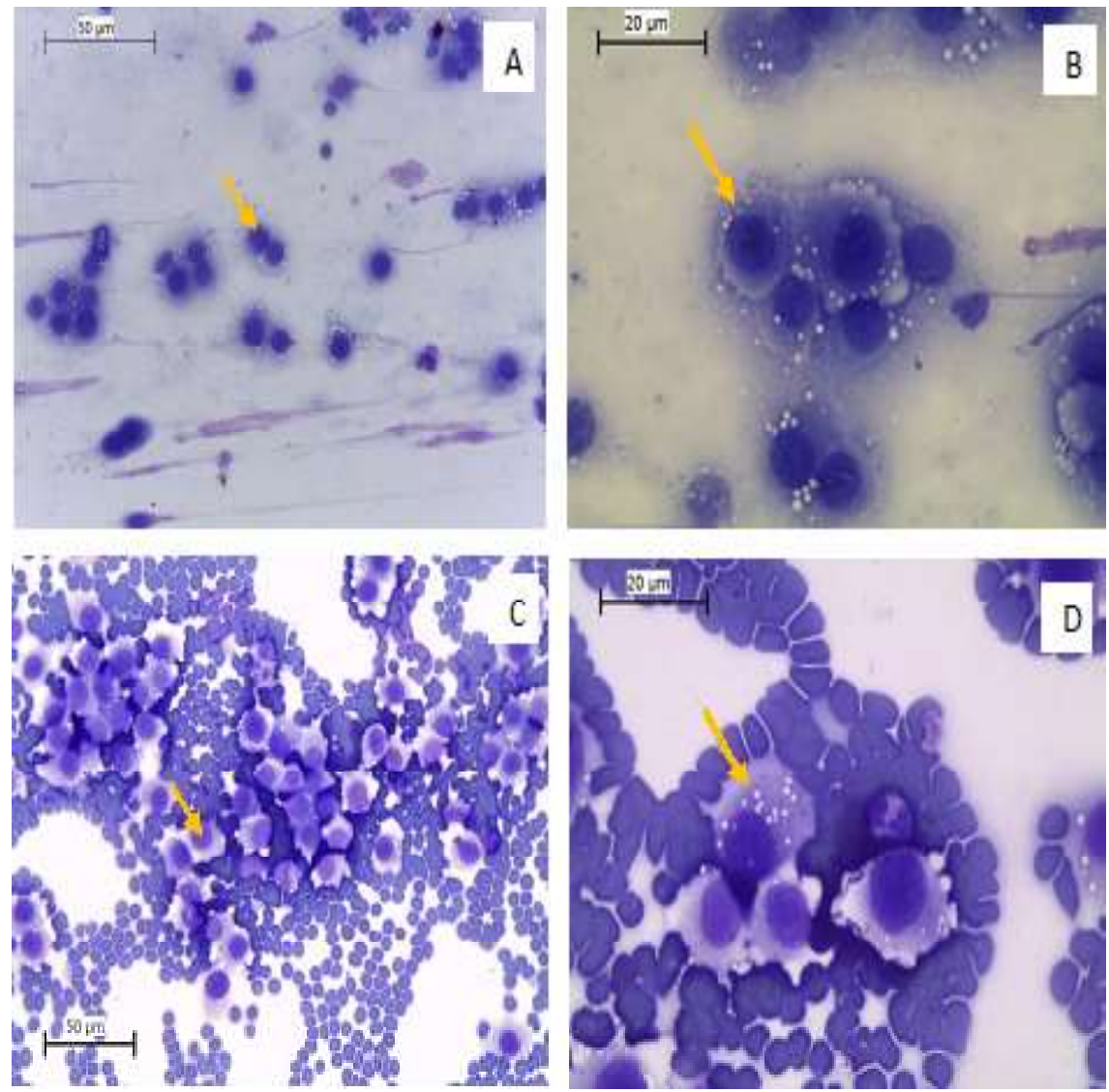

Figura 2. Clasificación citomorfológica del tumor venéreo transmisible canino (TVTC). Linfocitoide. 40x (A) y 100x (B). Plasmocitoide. 40x (C) y 100x (D). Coloración Diff Quick

\section{Tratamiento}

Se realizó una evaluación clínica inicial de cada paciente registrando los datos en un historial médico desde su ingreso al estudio, así como la evolución clínica durante el tratamiento. Para realizar la quimioterapia se tuvo en cuenta que las plaquetas estuviesen en valores superiores a las $200000 / \mu 1$. Se aplicó una infusión intravenosa semanal con sulfato de vincristina en dosis de $0.5 \mathrm{mg} / \mathrm{m}^{2}$ durante varias semanas hasta comprobar la involución total de la neoplasia, mediante colposcopia en las hembras y observación directa del pene en los machos.

\section{Análisis Estadístico}

Se evaluó la relación a la respuesta al tratamiento con el estado histopatológico en todos los pacientes, así como con los tres subtipos citomorfológicos. Se utilizó la prueba de Chi cuadrado con el programa Stata ${ }^{\circledR} 14$.

\section{Resultados}

En el laboratorio de patología veterinaria ingresaron 838 casos de caninos (521 de razas puras y 317 de raza mestiza) con algún tipo de neoplasia durante el periodo del estu- 

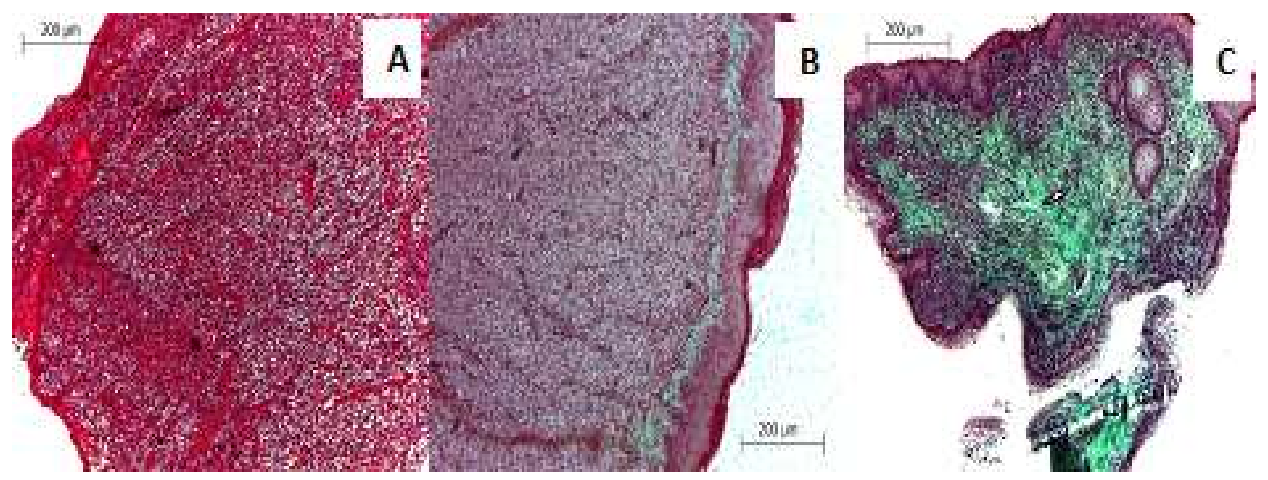

Figura 3. Etapas histológicas del tumor venéreo transmisible canino (TVTC) establecidas por Mukaratirwa et al. (2004). A. Proliferación. B. Regresión temprana. C. Regresión tardía. Fotografias tomadas con el lente $10 x$

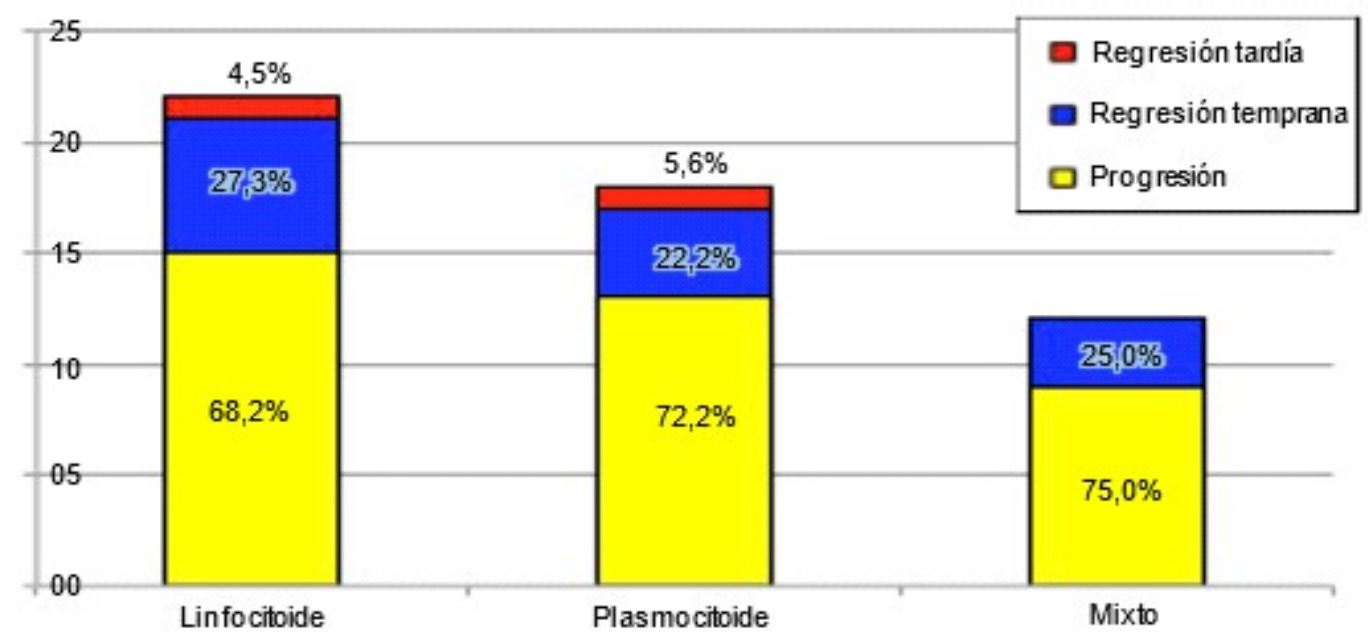

Figura 4. Proporción de subtipos citológicos del tumor venéreo transmisible canino (TVTC) en las tres fases histopatológicas

dio. De estos, 52 caninos llegaron naturalmente enfermos por TVTC genital, donde el $67.3 \%(35 / 52)$ fueron hembras y el $32.7 \%$ $(17 / 52)$ machos. Entre estos, el 2.3\% ( $n=12)$ correspondieron a caninos de razas puras y $12.6 \%(\mathrm{n}=40)$ a caminos mestizos.

El tratamiento con sulfato de vincristina fue efectivo en todos pacientes del estudio, requiriéndose cinco sesiones de quimioterapia en promedio para la involución tumoral, sin diferencia significativa para las variables analizadas. En cuanto a la citomorfología, $42.3 \%(22 / 52)$ de los pacientes fueron clasificados en el subtipo morfológico linfocitoide; $34.6 \%(18 / 52)$ como plasmocitoide y los restantes $23.1 \%$ (12/52) como mixtos.

La descripción morfológica de los subtipos celulares estuvo acorde con lo indicado en la literatura, pero adicionalmente se encontró que estas células tienen una mar- 
Cuadro 1. Número de quimioterapias requeridas para la involución total del tumor venéreo transmisible canino (TVTC) en pacientes clasificados por la fase histopatológica, seguido del subtipo citomorfológico

\begin{tabular}{llccc}
\hline $\begin{array}{l}\text { Fase } \\
\text { histopatológica }\end{array}$ & $\begin{array}{l}\text { Subtipo } \\
\text { citomorfológico }\end{array}$ & $\begin{array}{c}\text { Casos } \\
(\mathrm{n})\end{array}$ & $\begin{array}{c}\text { Quimioterapias } \\
(\text { media } \pm \mathrm{DE})\end{array}$ & p-valor \\
\hline Proliferación & Linfocitoide & 15 & $5.06 \pm 2.05$ & 0.26 \\
& Plasmocitoide & 13 & $5.78 \pm 1.64$ & 0.24 \\
& Mixto & 9 & $4.44 \pm 1.88$ & 0.26 \\
Regresión & Linfocitoide & 6 & $5.85 \pm 2.14$ & 0.30 \\
temprana & Plasmocitoide & 4 & $4.80 \pm 1.41$ & 0.30 \\
Regresión & Mixto & 3 & $5.33 \pm 2.08$ & 0.32 \\
tardía & Linfocitoide & 1 & 6 & \\
& Plasmocitoide & 1 & 4 & \\
& Mixto & 0 & 0 & \\
\hline Total & & 52 & & \\
\hline
\end{tabular}

cada anisocitosis y son más grandes que los linfocitos y polimorfonucleares que generalmente acompañan el tumor. Las células linfocitoides midieron entre 18.48 y $28.32 \mu \mathrm{m}$ $(21.4 \pm 3.6 \mu \mathrm{m})$ con núcleos que oscilaron entre los 10.5 y $18.4 \mu \mathrm{m}(14.3 \pm 2.3 \mu \mathrm{m})$, mostrando un valor en la relación núcleo/citoplasma de 1:1.5 para este subtipo. El tamaño de las células plasmocitoides estuvo entre 28.4 y 51.95 $\mu \mathrm{m}(34.2 \pm 5.9 \mu \mathrm{m})$; mientras su núcleo midió entre 13.6 y $22.05 \mu \mathrm{m}(16.6 \pm 2.6 \mu \mathrm{m})$, siendo la relación núcleo/citoplasma de 1:2.

Por otro lado, y respecto a las fases histopatológicas se encontró que $71.2 \%$ (37/52) de los pacientes presentaron tumores en etapa de progresión, 25\% (13/52) en etapa de regresión temprana y $3.8 \%(2 / 52)$ en regresión tardía (Cuadro 1). Estos dos últimos pacientes eran hembras, cuyos subtipos citológicos y presentación macroscópica correspondió en un caso a una linfocitoide con un tumor de consistencia firme y nodulado y en otro caso a un plasmocitoide con un tumor friable en forma de coliflor, los cuales requirieron 6 y 4 sesiones de quimioterapia, respectivamente.

Los subtipos citológicos se presentaron en las tres fases histopatológicas (Figura 4). Se encontró que el $68.2 \%$ (15/22), $72.2 \%(13 / 18)$ y $75 \%(9 / 12)$ de los casos linfocitoides, plasmocitoides y mixtos, estaban en fase de progresión, respectivamente. De igual manera, al relacionar la histopatología con los subtipos citológicos se encontró que 37 pacientes cuyos tumores estaban en progresión, donde el $40.5 \%(15 / 37)$ se clasificaron citológicamente como linfocitoides, $35.1 \%$ (13/37) como plasmocitoides y el 24.3\% (9/ 37) como mixtos (Cuadro 1). 


\section{Discusión}

Todos los pacientes presentaron una o varias masas tumorales en el área genital, diagnosticándose clínica, citológica, histopatológica y molecularmente como perros afectados por TVTC, aunque se desconocía el tiempo de evolución de la neoplasia. La mayoría de estos fueron hembras mestizas, lo cual coincide con Brandão et al. (2002); Amaral et al. (2007) y Oliveira et al. (2013). Ningún caso fue considerado como resistente, ya que todos los pacientes mostraron regresión total del tumor con el tratamiento empleado.

Respecto a la clasificación de los subtipos citológicos de los tumores, se encontraron más pacientes con TVTC linfocitoide, seguidos por plasmocitoide y por último mixto, contrario a otros reportes que indican un mayor número de tumores de tipo plasmocitoide, seguidos por el mixto y en menor frecuencia por linfocitoide (Gaspar et al., 2010; Oliveira et al., 2013; Setthawongsin et al., 2018), y al estudio de Fêo et al. (2018) quienes solo observaron el tipo plasmocitoide.

Estudios previos demuestran que la infiltración intra-tumoral de linfocitos es mayor en la fase de regresión comparada con la fase de progresión (Hsiao et al., 2002), incrementando gradualmente el infiltrado de una fase a otra (Liao et al., 2003); asimismo, Pérez et al. (1998) sugieren que no solo los linfocitos $\mathrm{T}$ sino las células plasmáticas participan en una efectiva respuesta inmune contra TVTC mediante la producción de anticuerpos y macrófagos. En este sentido, Frampton et al. (2018) analizaron biopsias de TVTC de pacientes tratados con vincristina y observaron que algunas expresiones de genes ocurrían paralelamente con los cambios histopatológicos, mostrando que la regresión tumoral ocurre en pasos secuenciales implicando la activación del sistema inmune innato y la infiltración inmunitaria del tumor. En el presente estudio, si bien no se realizó una marcación o medición de las posibles células implicadas en la respuesta inmune contra el TVTC, se pudo evidenciar que la sola clasificación histopatológica no establece ningún pronóstico con respecto al tiempo de tratamiento, pues no se evidenciaron diferencias significativas en el número de quimioterapias requeridas para la involución total del tumor.

En el análisis de los subtipos citológicos de los tumores relacionadas con las fases histopatológicas no se pudo concluir ninguna relación entre ellas, además de evidenciarse que no es posible definir solo con el subtipo citológico el estado histopatológico en el cual llega el paciente antes de comenzar tratamiento quimioterapéutico. Debido a que en este estudio los pacientes fueron afectados naturalmente con TVTC y se desconocía el tiempo de evolución tumoral, no se pudo tener un punto de partida similar u homogéneo para todos los pacientes. Estudios experimentales realizados en ratones han mostrado que las células de TVTC mantienen sus características citológicas, histológicas y moleculares (Harmelin et al., 2002), además que este modelo facilitaría el estudio de trasplante, progresión y metástasis del TVTC (Harmelin et al., 2001). Esto permite sugerir la ejecución de estudios experimentales en ratones que permitan tener un control y registro de los tiempos en que desarrolla esta neoplasia y la respuesta a tratamiento en cada una de las fases.

Es importante mencionar que se presentaron nueve casos TVTC extragenital en cavidad nasal que no fueron incluidos en los análisis debido a la dificultad de la obtención de la muestra por biopsia incisional. Igualmente se debe indicar que ninguno de los 52 pacientes analizados se evidenció desarrollo de metástasis, contrario a los reportes de Amaral et al. (2007) y Setthawongsin et al. (2018) que sugieren que el tipo plasmocitoide tiene una mayor capacidad de desarrollo extragenital y de metástasis. En forma similar, si bien no se observó resistencia o diferencias en el número de semanas de tratamiento con sulfato de vincristina, Valençola 
et al. (2015) y Simermann et al. (2009) encontraron que el subtipo plasmocitoide requiere de más sesiones de tratamiento y en algunos casos presentaron resistencia a este.

Se puede concluir que los resultados presentados no mostraron relación entre las clasificaciones analizadas y factores como respuesta parcial al tratamiento, grado de benignidad o malignidad tumoral, metástasis o resistencia al medicamento. Este estudio podría contribuir a generar investigaciones moleculares o genéticas que profundicen en las reales diferencias e importancias que estos subtipos y fases puedan tener en la patogénesis del TVTC y si existe algún posible pronóstico de respuesta al tratamiento.

\section{Literatura Citada}

1. Amaral A, Bassani-Silva S, Ferreira I, Santos L, Henrique F, De Andrade E, Fernando L, Gaspar J, et al. 2007. Cytomorphological characterization of transmissible canine venereal tumor. Rev Port Cienc Vet 102: 253-260.

2. Brandão CV, Gonçalves Borges A, Titton Ranzani J, Teixeira CR, Rahal SC, Rocha NS. 2002. Tumor venéreo transmissível: estudo retrospectivo de 127 casos (1998 - 2000). Rev Educación Continua 5: 25-31.

3. Castro KF, Strakova A, Tinucci-Costa M, Murchison EP. 2017. Evaluation of a genetic assay for canine transmissible venereal tumour diagnosis in Brazil. Vet Comp Oncol 15: 615-618. doi: 10.1111/ vco. 12205

4. Epstein RB, Bennett BT. 1974. Histocompatibility typing and course of canine venereal tumors transplanted into unmodified random dogs. Cancer Res 34: 788-793.

5. Ballestero Fêo H, Montoya Flórez L, Yamatogi RS, Prado Duzanski A, Araújo JP, Oliveira RA, Rocha NS. 2018. Does the tumour microen- vironment alter tumorigenesis and clinical response in transmissible venereal tumour in dogs? Vet Comp Oncol 16: 370-378. doi: 10.1111/vco. 12388

6. Frampton D, Schwenzer H, Marino G, Butcher LM, Pollara G, Kriston-Vizi J, Venturini C, et al. 2918. Molecular signatures of regression of the canine transmissible venereal tumor. Cancer Cell 33: 620-633. doi: 10.1016/ j.ccell.2018.03.003

7. Ganguly B, Das U, Das AK. 2016. Canine transmissible venereal tumour: a review. Vet Comp Oncol 14: 1-12. doi: 10.1111/vco. 12060

8. Gaspar LF, Amaral A, Bassani-Silva $S$, Rocha N. 2009. Imunorreatividade à glicoproteína-P nos diferentes tipos citomorfológicos de tumor venéreo transmissível canino. Veterinária em foco 6: 140-146.

9. Gaspar LF, Ferreira I, Moleta Colodel M, Seullner Brandão CV, Rocha NS. 2010. Spontaneous canine transmissible venereal tumor: cell morphology and influence on Pglycoprotein expression. Turk J Vet Anim Sci 34: 447-454

10. Harmelin A, Pinthus JH, FriedmannMorvinski D, Kaufman K, Brenner $O$. 2002. Lack of MHC expression and retention of ultrastructural characteristics by xenograft transmissible venereal tumor cells in SCID mice. Vet Immunol Immunop 86: 245-249. doi: 10.1016/ s0165-2427(02)00036-3

11. Harmelin A, Pinthus JH, Katzir N, Kapon A, Volcani Y, Amariglio EN, Rehavi G. 2001. Use of a murine xenograft model for canine transmissible venereal tumor. Am J Vet Res 62: 907 911. doi: 10.2460/ajvr.2001.62.907

12. Hsiao YW, Liao $\mathrm{KW}$, Hung $\mathrm{SW}$, Chu RM. 2002. Effect of tumor infiltrating lymphocytes on the expression of MHC molecules in canine transmissible venereal tumor cells. Vet Immunol Immunop 87: 19-27. doi: 10.1016/s01652427(02)00026-0 
13. Liao KW, Hung SW, Hsiao $Y W$, Bennett M, Chu RM. 2003. Canine transmissible venereal tumor cell depletion of B lymphocytes: molecule(s) specifically toxic for B cells. Vet Immunol Immunop 92: 149-162. doi: 10.1016/s0165-2427(03)00032-1

14. Montoya M, Pedraza F, Grandi F, Rocha NS. 2012. Cytologic subtypes of canine transmissible venereal tumor. Vet Clin Pathol 41: 4-5. doi: 10.1111/j.1939165X.2012.00401.X

15. Mukaratirwa S, Chimonyo M, Obwolo M, Gruys E, Nederbragt H. 2004. Stromal cells and extracellular matrix components in spontaneous canine transmissible venereal tumour at different stages of growth. Histol Histopathol 19: 1117-1123. doi: 10.14670/ HH-19.1117

16. Murchison EP. 2009. Clonally transmissible cancers in dogs and Tasmanian devils. Oncogene 27: S19-S30. doi: 10.1038/onc. 2009.350

17. Murchison EP, Wedge DC, Alexandrov $L B, F u B$, Martincorena I, Ning $Z$, Tubio JMC, et al. 2014. Transmissible [corrected] dog cancer genome reveals the origin and history of an ancient cell lineage. Science 343: 437-440. doi: $10.1126 /$ science. 1247167

18. Oliveira K, Quessada AM, Maria S, De Sousa M, Assis F. Costa L, Silva S, De Pinho FA, Ramon R, Barbosa F. 2013. Transmissible venereal tumor treated with autohemotherapy. Acta Sci Vet 55: 1-4.

19. Ostrander EA, Davis BW, Ostrander GK. 2016. Transmissible tumors: breaking the cancer paradigm. Trends Genet 32: 1-15. doi: 10.1016/j.tig.2015.10.001

20. Otter W, Hack M, Jacobs JJ, Tan JF, Rozendaal L, VAN Moorselaar RJ. 2015. Effective treatment of transmissible venereal tumors in dogs with vincristine and IL2. Anticancer Res 35: 3385-3391.
21. Pérez J, Day MJ, Mozos E. 1998. Immunohistochemical study of the local inflammatory infiltrate in spontaneous canine transmissible venereal tumour at different stages of growth. Vet Immunol Immunop 64: 133-147. doi: 10.1016/ s0165-2427(98)00131-7

22. Santos FG, Vasconcelos AC, Nunes JE, Cassali GD, Paixao TA, Moro L. 2005. O tumor venereo transmissivel canino -aspectos gerais e abordagens moleculares (revisão de literatura). Biosci J 21: 41-53.

23. Setthawongsin C, Tangkawattana $S$, Rungsipipat A, Techangamsuwan S. 2018. Computerized cytomorphometric and cytomorphological analysis of canine transmissible venereal tumours. J Comp Pathol 163: 18-22. doi: 10.1016/ j.jcpa.2018.07.003

24. Simermann N. 2009. Sulfato de vincristina no tratamento do tumor venéreo transmissível frente à caracterização citomorfológica. Tese do Mestrado. Brasil: Universidade Federal de Goias.

25. Sousa J, Saito V, Nardi A, Rodaski S, Guerios S, Bacila M. 2000. Características e incidência do tumor venéreo transmissível (tvt) em cães e eficiência da quimioterapia e outros tratamentos. Arch Vet Sci 5: 41-48.

26. Stockmann D, Ferrari HF, Andrade AL, Lopes RA, Tereza C, Luvizotto MCR. 2011. Canine Transmissible Venereal Tumors: Aspects Related to Programmed Cell Death. Braz J Vet Pathol 4: 67-75.

27. Strakova A, Murchison EP. 2014. The changing global distribution and prevalence of canine transmissible venereal tumour. BMC Vet Res 10: 168. doi: 10.1186/s12917-014-0168-9

28. Strakova A, Murchison EP. 2015. The cancer which survived: insights from the genome of an 11000 year-old cancer. Curr Opin Genet Dev 30: 49-55. doi: 10.1016/j.gde.2015.03.005 
29. Valençola RA, Antunes TR, Sorgatto $S$, Oliveira BB. 2015. Aspectos citomorfológicos e frequência dos subtipos do tumor venéreo transmissível canino no município de Campo Grande, Mato Grosso do Sul, Brasil. Acta Vet Bras 9: 82-86.
30. Yang TJ, Chandler JP, Dunne-Anway S. 1997. Growth stage dependent expression of MHC antigens on the canine transmissible venereal sarcoma. Brit J Cancer 55: 131-134. doi: 10.1038/ bjc. 1987.27 